\title{
Behaviour and Optimization Aids of Composite Stiffened Hypar Shell Roofs with Cutout under Free Vibration
}

\author{
Sarmila Sahoo \\ Department of Civil Engineering, Meghnad Saha Institute of Technology, Kolkata 700107, India \\ Correspondence should be addressed to Sarmila Sahoo, sarmila_ju@yahoo.com
}

Received 22 February 2012; Accepted 19 April 2012

Academic Editor: I. Smith

Copyright () 2012 Sarmila Sahoo. This is an open access article distributed under the Creative Commons Attribution License, which permits unrestricted use, distribution, and reproduction in any medium, provided the original work is properly cited.

A scrutiny of the literature reveals that the free vibration characteristics of stiffened composite hypar shell with cutout are missing. So a generalized finite element formulation for the stiffened hyperbolic paraboloidal shells bounded by straight edges (commonly called as hypar shells) is attempted using an eight-noded curved quadratic isoparametric element for shell with a three-noded beam element for stiffener. Numerical problems of earlier investigators are solved as benchmark problems to validate the approach. A number of problems are further solved by varying the size of the cutouts and their positions with respect to the shell centre for different edge constraints. The results are presented in the form of figures and tables. The results are further analysed to suggest guidelines to select optimum size and position of the cutout with respect to shell centre considering the different practical constraints.

\section{Introduction}

The advent of laminated composites in civil engineering applications has provided a new impetus to the researchers to explore the different aspects of composite structural elements including different forms of shells. A skewed hypar shell is aesthetically appealing and being doubly ruled is easy to cast. Moreover, this configuration can allow entry of north light and due to this advantage it finds use as roofing units in practical civil engineering situations. Shell structures that are normally thin-walled exhibit improved performances with stiffeners, particularly when the shell surface is provided with cutouts. Cutout is sometimes necessary in roof structure for the passage of light, to provide accessibility to other parts of the structure, for venting and also sometimes for alteration of resonant frequency. Basic knowledge of the free vibration characteristics of stiffened composite skewed hypar shell with cutout is essential for using these forms confidently.

As early as in 1982, Reddy [1] carried out the finite element analysis of composite plate with cutout and presented the effects of parametric variations on linear and nonlinear frequencies. Later in 1989, Malhotra et al. [2] presented the effect of fibre orientation and size of cutout on natural frequency on orthotropic square plates with square cutouts for different boundary conditions using the Rayleigh-Ritz method. Sivasubramonian et al. [3] reported free vibration of curved panels with cutout. They analysed the effect of cutouts on the natural frequencies of plates with some classical boundary conditions. Later Sivakumar et al. [4], Rossi [5], Huang and Sakiyama [6], and Hota and Padhi [7] studied free vibration of plate with various cutout geometries. Chakravorty et al. [8] reported some results in order to study the effect of concentric cutout on natural frequency of different shell options. In 1999, Sivasubramonian et al. [9] studied the free vibration characteristics of longitudinally stiffened square panels with symmetrical square cutouts by using the finite element method. The size of the cutout (symmetrically located) as well as curvature of the panels is varied. Hota and Chakravorty [10] published useful information about free vibration of stiffened conoidal shell roofs with cutout. Later, Nanda and Bandyopadhyay [11] investigated the effect of different parametric variation on nonlinear free vibration characteristics of cylindrical shell with cutout. The finite element model using an eight-noded $\mathrm{C}^{0}$ continuity, isoparametric quadrilateral element is used to study the dynamic behaviour. In a recent paper, Sahoo [12] carried out detailed free vibration analysis of composite unstiffened hypar shells with different practical boundary conditions. 


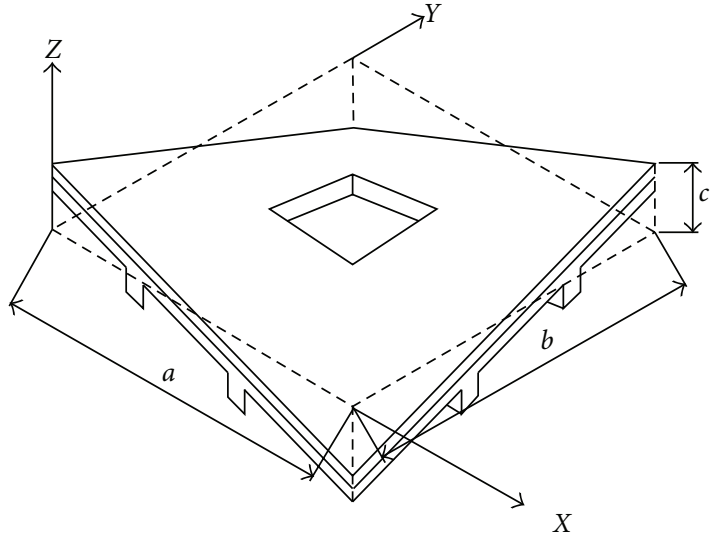

Surface equation: $z=\frac{4 c}{a b}(x-a / 2)(y-b / 2)$

FIGURE 1: Surface of a stiffened hypar shell with cutout.

Thus, it is found that results of free vibration characteristics of isotropic as well as composite stiffened composite shell panels with cutout are scanty in the existing body of literature. Only Chakravorty et al. [8] deals with some results of free vibration of hypar shell with concentric cutout, but to the best of author knowledge information regarding the free vibration behaviour of composite stiffened hypar shell with cutout is missing in the literature. In the present paper the free vibration of stiffened hypar shell with cutouts (Figure 1) is studied considering different boundary conditions. The variation of fundamental frequency due to change in eccentricity of cutout along $x$ and $y$ direction is also considered.

\section{Mathematical Formulation}

2.1. Finite Element Formulation for Shell. A laminated composite hypar shell of uniform thickness $h$ (Figure 2) and twist radius of curvature $R_{x y}$ is considered. Keeping the total thickness the same, the thickness may consist of any number of thin laminae each of which may be arbitrarily oriented at an angle $\theta$ with reference to the $X$-axis of the coordinate system. An eight-noded curved quadratic isoparametric finite element (Figure 3 ) is used. The five degrees of freedom taken into consideration at each node include two in-plane and one transverse displacement and two rotations about the $X$ - and $Y$-axes. Sahoo and Chakravorty [13] reported in an earlier paper the strain displacement and constitutive relationships together with the systematic development of stiffness matrix for the shell element.

\subsection{Finite Element Formulation for Stiffener of the Shell.} Three noded curved isoparametric beam elements (Figure 3) are used to model the stiffeners, which are taken to run only along the boundaries of the shell elements. In the stiffener element, each node has four degrees of freedom that is $u_{s x}$, $w_{s x}, \alpha_{s x}$, and $\beta_{s x}$ for $X$-stiffener and $v_{s y}, w_{s y}, \alpha_{s y}$, and $\beta_{s y}$ for $Y$-stiffener. The generalized force-displacement relation

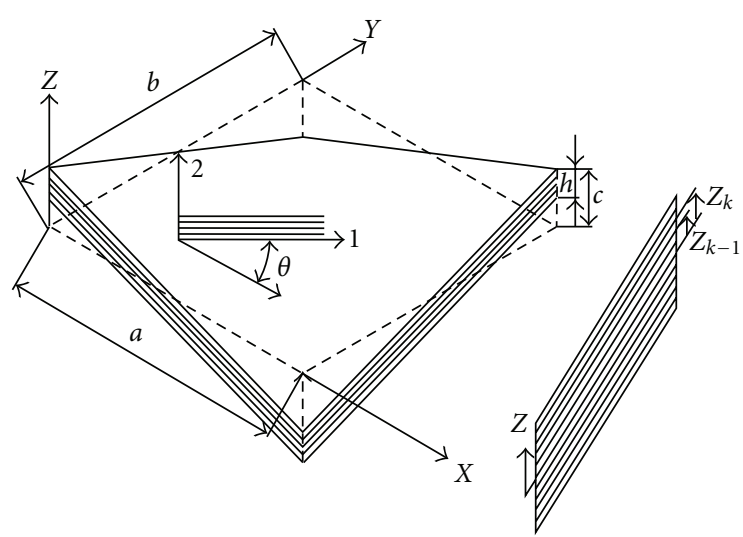

FIgUre 2: Laminations in skewed hypar shell.

of stiffeners can be expressed as (the notations have been defined in the nomenclature):

$$
\begin{gathered}
X \text {-stiffener: }\left\{F_{s x}\right\}=\left[D_{s x}\right]\left\{\varepsilon_{s x}\right\}=\left[D_{s x}\right]\left[B_{s x}\right]\left\{\delta_{s x i}\right\} ; \\
Y \text {-stiffener: }\left\{F_{s y}\right\}=\left[D_{s y}\right]\left\{\varepsilon_{s y}\right\}=\left[D_{s y}\right]\left[B_{s y}\right]\left\{\delta_{s y i}\right\},
\end{gathered}
$$

where $\left\{F_{s x}\right\}=\left[\begin{array}{llll}N_{s x x} & M_{s x x} & T_{s x x} & Q_{s x x z}\end{array}\right]^{T} ;\left\{\varepsilon_{s x}\right\}=\left[u_{s x . x}\right.$

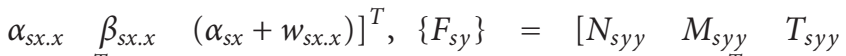
$\left.Q_{s y y z}\right]^{T} ;\left\{\varepsilon_{s y}\right\}=\left[\begin{array}{llll}v_{s y . y} & \beta_{s y \cdot y} & \alpha_{s y \cdot y} & \left(\beta_{s y}+w_{s y . y}\right)\end{array}\right]^{T}$.

Elasticity matrices are as follows:

$$
\begin{aligned}
& {\left[D_{s x}\right]=\left[\begin{array}{cccc}
A_{11} b_{s x} & B_{11}^{\prime} b_{s x} & B_{12}^{\prime} b_{s x} & 0 \\
B_{11}^{\prime} b_{s x} & D_{11}^{\prime} b_{s x} & D_{12}^{\prime} b_{s x} & 0 \\
B_{12}^{\prime} b_{s x} & D_{12}^{\prime} b_{s x} & \frac{1}{6}\left(\mathrm{Q}_{44}+\mathrm{Q}_{66}\right) d_{s x} b_{s x}^{3} & 0 \\
0 & 0 & 0 & b_{s x} S_{11}
\end{array}\right],} \\
& {\left[D_{s y}\right]=\left[\begin{array}{cccc}
A_{22} b_{s y} & B_{22}^{\prime} b_{s y} & B_{12}^{\prime} b_{s y} & 0 \\
B_{22}^{\prime} b_{s y} & \frac{1}{6}\left(Q_{44}+Q_{66}\right) b_{s y} & D_{12}^{\prime} b_{s y} & 0 \\
B_{12}^{\prime} b_{s y} & D_{12}^{\prime} b_{s y} & D_{11}^{\prime} d_{s y} b_{s y}^{3} & 0 \\
0 & 0 & 0 & b_{s y} S_{22}
\end{array}\right],}
\end{aligned}
$$

where

$$
D_{i j}^{\prime}=D_{i j}+2 e B_{i j}+e^{2} A_{i j} ; \quad B_{i j}^{\prime}=B_{i j}+e A_{i j},
$$

and $A_{i j}, B_{i j}, D_{i j}$, and $S_{i j}$ are explained in an earlier paper by Sahoo and Chakravorty [13].

Here the shear correction factor is taken as 5/6. The sectional parameters are calculated with respect to the midsurface of the shell by which the effect of eccentricities of stiffeners is automatically included. The element stiffness matrices are of the following forms:

$$
\begin{aligned}
\text { for } X \text {-stiffener: }\left[K_{x e}\right] & =\int\left[B_{s x}\right]^{\mathrm{T}}\left[D_{s x}\right]\left[B_{s x}\right] d x ; \\
\text { for } Y \text {-stiffener: }\left[K_{y e}\right] & =\int\left[B_{s y}\right]^{\mathrm{T}}\left[D_{s y}\right]\left[B_{s y}\right] d y .
\end{aligned}
$$

The integrals are converted to isoparametric coordinates and are carried out by 2-point Gauss quadrature. Finally, the 


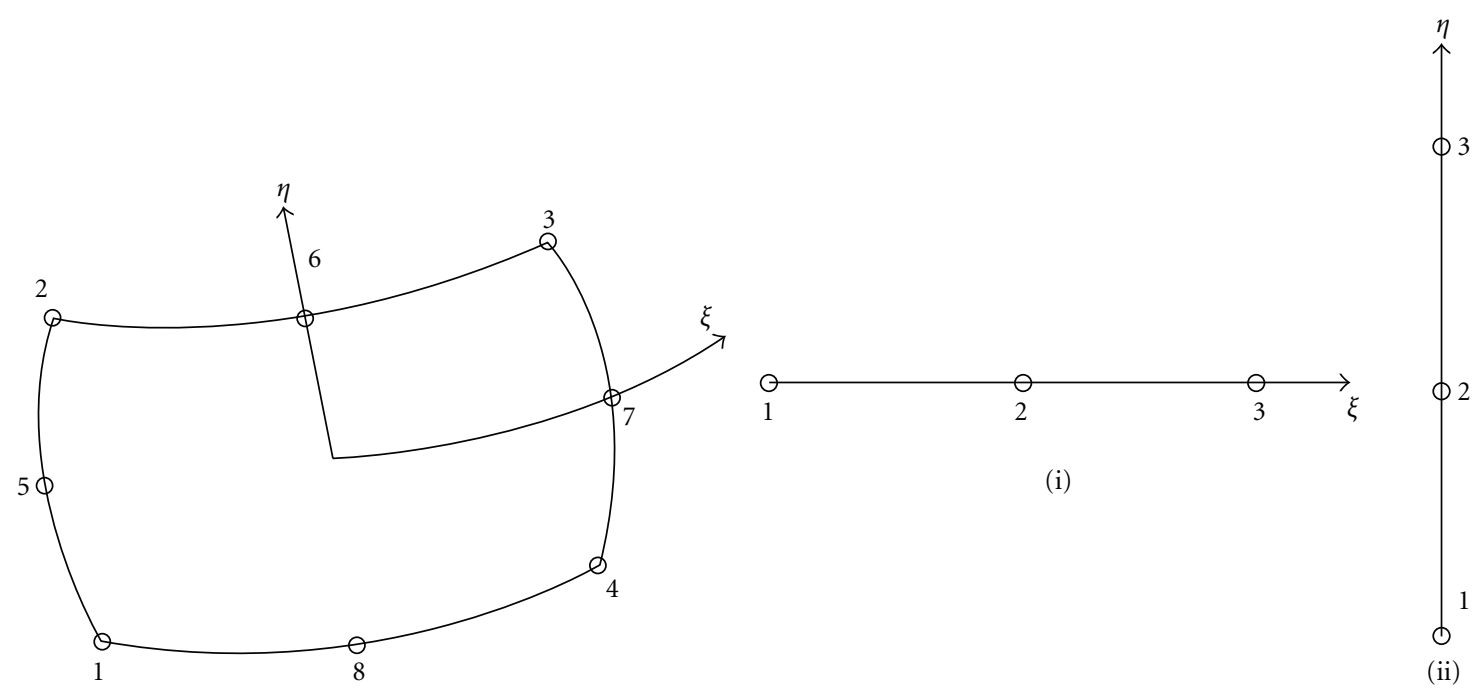

(a)

(b)

FIGURE 3: (a) Eight-noded shell element with isoparametric coordinates. (b) Three-noded stiffener element-(i) $X$-stiffener and (ii) $Y$-stiffener.

element stiffness matrix of the stiffened shell is obtained by in which appropriate matching of the nodes of the stiffener and shell elements through the connectivity matrix and is given as

$$
\left[K_{e}\right]=\left[K_{\text {she }}\right]+\left[K_{x e}\right]+\left[K_{y e}\right]
$$

The element stiffness matrices are assembled to get the global matrices.

2.3. Element Mass Matrix. The element mass matrix for shell is obtained from the integral

$$
\left[M_{e}\right]=\iint[N]^{T}[P][N] d x d y,
$$

where

$$
[N]=\sum_{i=1}^{8}\left[\begin{array}{ccccc}
N_{i} & 0 & 0 & 0 & 0 \\
0 & N_{i} & 0 & 0 & 0 \\
0 & 0 & N_{i} & 0 & 0 \\
0 & 0 & 0 & N_{i} & 0 \\
0 & 0 & 0 & 0 & N_{i}
\end{array}\right], \quad[P]=\sum_{i=1}^{8}\left[\begin{array}{ccccc}
P & 0 & 0 & 0 & 0 \\
0 & P & 0 & 0 & 0 \\
0 & 0 & P & 0 & 0 \\
0 & 0 & 0 & I & 0 \\
0 & 0 & 0 & 0 & I
\end{array}\right],
$$

$$
P=\sum_{k=1}^{n p} \int_{z_{k-1}}^{z_{k}} \rho d z, \quad I=\sum_{k=1}^{n p} \int_{z_{k-1}}^{z_{k}} z \rho d z .
$$

Element mass matrix for stiffener element

Here, $[\mathrm{N}]$ is a $3 \times 3$ diagonal matrix.

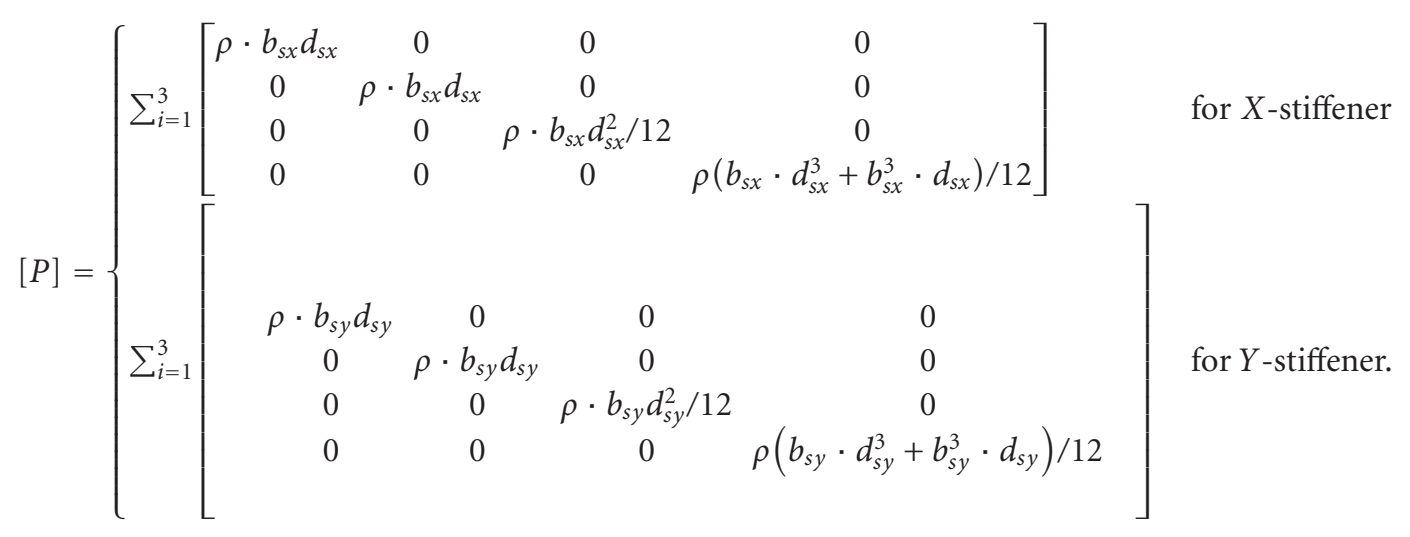


TABLE 1: Natural frequencies $(\mathrm{Hz})$ of centrally stiffened clamped square plate.

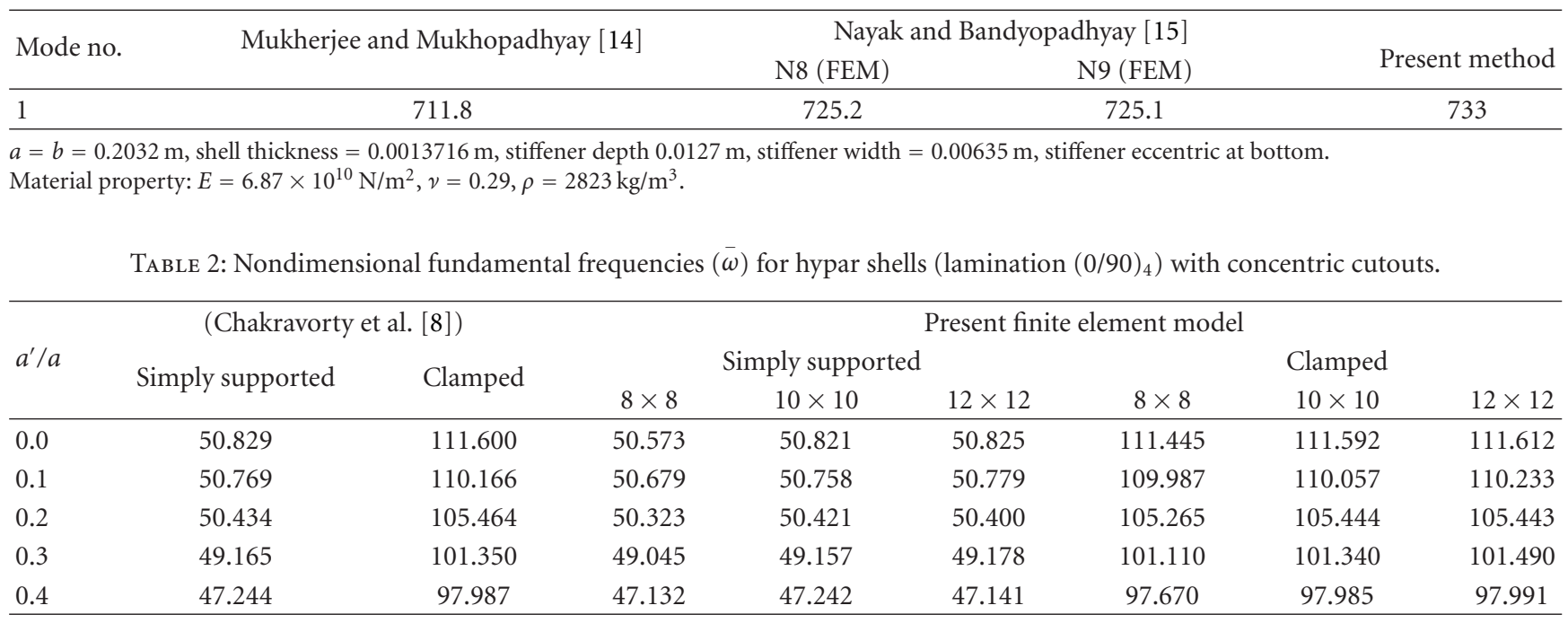

$a / b=1, a / h=100, a^{\prime} / b^{\prime}=1, c / a=0.2 ; E_{11} / E_{22}=25, G_{23}=0.2 E_{22}, G_{13}=G_{12}=0.5 E_{22}, v_{12}=v_{21}=0.25$.

The mass matrix of the stiffened shell element is the sum of the matrices of the shell and the stiffeners matched at the appropriate nodes.

$$
\left[M_{e}\right]=\left[M_{\text {she }}\right]+\left[M_{x e}\right]+\left[M_{y e}\right] .
$$

The element mass matrices are assembled to get the global matrices.

2.4. Modeling the Cutout. The code developed can take the position and size of cutout as input. The program is capable of generating nonuniform finite element mesh all over the shell surface. So the element size is gradually decreased near the cutout margins. One such typical mesh arrangement is shown in Figure 4. Such finite element mesh is redefined in steps and a particular grid is chosen to obtain the fundamental frequency when the result does not improve by more than one percent on further refining. Convergence of results is ensured in all the problems taken up here.

2.5. Solution Procedure for Free Vibration Analysis. The free vibration analysis involves determination of natural frequencies from the condition

$$
\left|[K]-\omega^{2}[M]\right|=0 .
$$

This is a generalized eigenvalue problem and is solved by the subspace iteration algorithm.

\section{Validation Study}

The results of Table 1 show that the agreement of present results with the earlier ones is excellent and the correctness of the stiffener formulation is established. Free vibration of simply supported and clamped hypar shell with $(0 / 90)_{4}$ lamination with cutouts is also considered. The fundamental frequencies of hypar shell with cutout obtained by

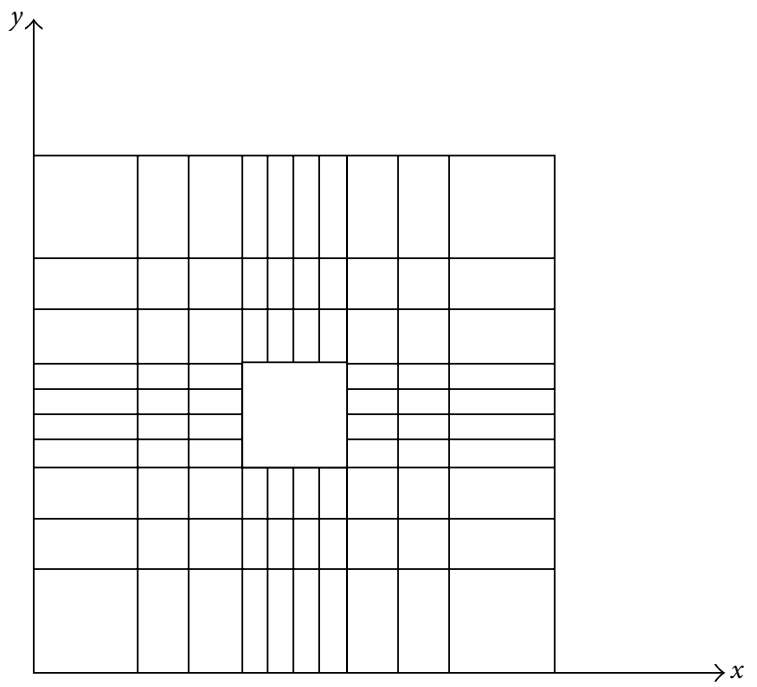

Figure 4: Typical $10 \times 10$ nonuniform mesh arrangements drawn to scale.

the present method agree well with those reported by Chakravorty et al. [8] as evident from Table 2, establishing the correctness of the cutout formulation. Thus, it is evident that the finite element model proposed here can successfully analyse vibration problems of stiffened skewed hypar composite shells with cutout which is reflected by close agreement of present results with benchmark ones.

The present approach uses the improved first order approximation theory for thin shells [16] considering the radius of cross curvature. For this class of thin shells, a shear correction factor of unity is found to yield good results. It is observed that the results remain the same when analysis is repeated with the commonly used shear correction factor of $\pi / \sqrt{12}$. 
TABle 3: Values of " $p$ " for 0/90/0/90 hypar shell.

\begin{tabular}{|c|c|c|c|c|c|}
\hline \multirow{2}{*}{ Boundary conditions } & \multicolumn{5}{|c|}{ Cutout size $\left(a^{\prime} / a\right)$} \\
\hline & 0 & 0.1 & 0.2 & 0.3 & 0.4 \\
\hline CCCC & 0 & 1.67 & -0.20 & -1.76 & -3.56 \\
\hline CSCC & 0 & 1.04 & -0.47 & -2.26 & -4.2 \\
\hline CCSC & 0 & 0.95 & -0.60 & -2.54 & -4.56 \\
\hline CCCS & 0 & -1.02 & -0.47 & -2.32 & -4.22 \\
\hline CSSC & 0 & 0.0 & -1.97 & -5.43 & -9.42 \\
\hline CCSS & 0 & 0.0 & -1.94 & -5.41 & 9.41 \\
\hline CSCS & 0 & 12.48 & 21.21 & 27.74 & 27.51 \\
\hline SCSC & 0 & 12.17 & 21.25 & 29.32 & 28.51 \\
\hline CSSS & 0 & 12.70 & 19.87 & 24.70 & 23.50 \\
\hline SSSC & 0 & 12.67 & 19.92 & 24.99 & 23.75 \\
\hline SSCS & 0 & 12.77 & 19.87 & 24.68 & 23.49 \\
\hline SSSS & 0 & 13.61 & 21.53 & 29.00 & 32.20 \\
\hline
\end{tabular}

$a / b=1, a / h=100, a^{\prime} / b^{\prime}=1, c / a=0.2 ; E_{11} / E_{22}=25, G_{23}=0.2 E_{22}, G_{13}=G_{12}=0.5 E_{22}, v_{12}=v_{21}=0.25, b_{\mathrm{st}} / h=1, d_{\mathrm{st}} / h=2$. Each stiffener has a single lamina with fibres along its length.

TABLE 4: Values of “ $p$ ” for $+45 /-45 /+45 /-45$ hypar shell.

\begin{tabular}{|c|c|c|c|c|c|}
\hline \multirow{2}{*}{ Boundary conditions } & \multicolumn{5}{|c|}{ Cutout size $\left(a^{\prime} / a\right)$} \\
\hline & 0 & 0.1 & 0.2 & 0.3 & 0.4 \\
\hline CCCC & 0 & 0.08 & -1.2 & -7.4 & -16.29 \\
\hline CSCC & 0 & 1.13 & -6.11 & -21.59 & -29.25 \\
\hline CCSC & 0 & 0.67 & -5.84 & -21.9 & -28.99 \\
\hline CCCS & 0 & 0.75 & -5.78 & -21.96 & -29.22 \\
\hline CSSC & 0 & -0.82 & -5.14 & -12.44 & -24.09 \\
\hline CCSS & 0 & -0.97 & -5.18 & -12.77 & -24.19 \\
\hline CSCS & 0 & 0.99 & 0.53 & 1.53 & 1.52 \\
\hline SCSC & 0 & 0.93 & 0.53 & -0.01 & 1.87 \\
\hline CSSS & 0 & 0.77 & 0.64 & 1.36 & -0.29 \\
\hline SSSC & 0 & 0.74 & 0.64 & 1.34 & -0.07 \\
\hline SSCS & 0 & 0.58 & 0.64 & 1.35 & -0.3 \\
\hline SSSS & 0 & 0.44 & 0.8 & 1.66 & 0.36 \\
\hline
\end{tabular}

$a / b=1, a / h=100, a^{\prime} / b^{\prime}=1, c / a=0.2 ; E_{11} / E_{22}=25, G_{23}=0.2 E_{22}, G_{13}=G_{12}=0.5 E_{22}, v_{12}=v_{21}=0.25, b_{s t} / h=1, d_{s t} / h=2$. Each stiffener has a single lamina with fibres along its length.

TABLE 5: Clamping options for 0/90/0/90 hypar shells with central cutouts having $a^{\prime} / a$ ratio 0.2 .

\begin{tabular}{|c|c|c|c|}
\hline $\begin{array}{l}\text { Number of sides to be } \\
\text { clamped }\end{array}$ & Clamped edges & $\begin{array}{l}\text { Improvement of frequencies with } \\
\text { respect to simply supported shells }\end{array}$ & $\begin{array}{l}\text { Marks indicating the } \\
\text { efficiencies of clamping }\end{array}$ \\
\hline 0 & $\begin{array}{c}\text { Simply supported no edges clamped } \\
\text { (SSSS) }\end{array}$ & - & 0 \\
\hline \multirow{3}{*}{1} & (a) Along $x=0$ (CSSS) & Good improvement & 21 \\
\hline & (b) Along $x=a$ (SSCS) & Good improvement & 21 \\
\hline & (c) Along $y=b$ (SSSC) & Good improvement & 21 \\
\hline \multirow{2}{*}{2} & (a) Two alternate edges (CSCS, SCSC) & Very good improvement & 51 \\
\hline & (b) Two adjacent edges (CSSC, CCSS) & Marked improvement & 71 \\
\hline \multirow{3}{*}{3} & 3 edges excluding $y=0$ CSCC & \multirow{3}{*}{$\begin{array}{l}\text { Remarkable improvement and } \\
\text { frequency becomes almost equal to } \\
\text { that of fully clamped shells }\end{array}$} & 85 \\
\hline & 3 edges excluding $x=a$ CCSC & & 85 \\
\hline & 3 edges excluding $y=b$ CCCS & & 85 \\
\hline 4 & All sides (CCCC) & Frequency attains a maximum value & 100 \\
\hline
\end{tabular}


TABLE 6: Clamping options for $+45 /-45 /+45 /-45$ hypar shells with central cutouts having $a^{\prime} / a$ ratio 0.2 .

\begin{tabular}{|c|c|c|c|}
\hline $\begin{array}{l}\text { Number of sides to be } \\
\text { clamped }\end{array}$ & Clamped edges & $\begin{array}{l}\text { Improvement of frequencies with respect } \\
\text { to simply supported shells }\end{array}$ & $\begin{array}{l}\text { Marks indicating the } \\
\text { efficiencies of clamping }\end{array}$ \\
\hline 0 & $\begin{array}{l}\text { Simply supported no edges clamped } \\
\text { (SSSS) }\end{array}$ & - & 0 \\
\hline \multirow{3}{*}{1} & (a) Along $x=0$ (CSSS) & Slight improvement & 9 \\
\hline & (b) Along $x=a$ (SSCS) & Slight improvement & 9 \\
\hline & (c) Along $y=b$ (SSSC) & Slight improvement & 9 \\
\hline \multirow{2}{*}{2} & (a) Two alternate edges (CSCS, SCSC) & Good improvement & 17 \\
\hline & (b) Two adjacent edges (CSSC, CCSS) & Good improvement & 31 \\
\hline \multirow{3}{*}{3} & 3 edges excluding $y=0$ CSCC & Very good improvement & 48 \\
\hline & 3 edges excluding $x=a$ CCSC & Very good improvement & 48 \\
\hline & 3 edges excluding $y=b$ CCCS & Very good improvement & 48 \\
\hline 4 & All sides (CCCC) & Frequency attains a maximum value & 100 \\
\hline
\end{tabular}

\section{Results and Discussion}

In order to study the effect of cutout size and position on the free vibration response, additional problems for hypar shells with 0/90/0/90 and $+45 /-45 /+45 /-45$ lamination and different boundary conditions have been solved. The selection of the 0/90/0/90 and $+45 /-45 /+45 /-45$ lamination is based on an earlier study by Sahoo and Chakravorty [13] which revealed that repeating $0 / 90$ unit and $+45 /-45$ unit more than once and keeping the total shell thickness constant does not improve the fundamental frequency to an appreciable extent. The positions of the cutouts are varied along both of the plan directions of the shell for different practical boundary conditions to study the effect of eccentricity of cutout on the fundamental frequency.

4.1. Free Vibration Behaviour of Shells with Concentric Cutouts. Figures 5 and 6 furnish the results of nondimensional frequency $(\bar{\omega})$ of $0 / 90 / 0 / 90$ and $+45 /-45 /+45 /-45$ stiffened hypar shells with cutout. The shells considered are of square plan form $(a=b)$ and the cutouts are also taken to be square in plan $\left(a^{\prime}=b^{\prime}\right)$. The cutouts placed concentrically on the shell surface. The cutout sizes (i.e., $a^{\prime} / a$ ) are varied from 0 to 0.4 and boundary conditions are varied along the four edges. The stiffeners are placed along the cutout periphery and extended up to the edge of the shell. The boundary conditions are designated by describing the support clamped or simply supported as $C$ or $S$ taken in an anticlockwise order from the edge $x=0$. This means a shell with CSCS boundary is clamped along $x=0$ and simply supported along $y=0$ and clamped along $x=a$ and simply supported along $y=b$. The material and geometric properties of shells and cutouts are mentioned along with the figures.

4.1.1. Effect of Cutout Sizes. From the figures it is seen that when a cutout is introduced to a stiffened shell the fundamental frequency increases in all the cases. This increasing trend is noticed for both cross-ply and angle-ply shells. This initial increase in frequency is due to the fact that with the introduction of cutout, numbers of stiffeners are increased from two to four in the present study. In order to study the effect of cutout size, in more details, the ratio of the fundamental frequency of a concentric punctured shell to that of a shell without cutout are expressed in percentage. The increase or decrease in percentage of fundamental frequency from the full shell is denoted by $p$. Tables 3 and 4 contain such $p$ values for $0 / 90 / 0 / 90$ and $+45 /-45 /+45 /-45$ shells, respectively. Negative sign indicates decrease in frequency. It is evident from Tables 3 and 4 that in all the cases with the introduction of cutout with $a^{\prime} / a=0.1$ the frequencies increase. But further increase in cutout size, that is, when $a^{\prime} / a=0.2$, fundamental frequency may increase or decrease. When the cutout size is further increased, but the number and dimensions of the stiffeners do not change, the shell surface undergoes loss of both mass and stiffness. It is evident from Tables 3 and 4 that when number of boundary constrains are more (shells with more clamped edges), loss of stiffness is more significant than loss of mass. Hence, fundamental frequency decreases except in case of clamped angle ply shell. For this shell when $a^{\prime} / a=0.2$, fundamental frequency increases but further increase of cutout size decreases the fundamental frequency. But for shells with less number of boundary constraints, the fundamental frequency increases with the increase in cutout sizes. This trend is true for both cross- and angle-ply shells.

In such cases, as the cutout grows in size, the loss of mass is more significant than loss of stiffness, and hence, the frequency increases. From Tables 3 and 4 , it is found that with introduction of a cutout of $a^{\prime} / a=0.2$, in shell surface, the decrease in frequency is not more than $5 \%$. This leads to the engineering conclusion that concentric cutouts with stiffened margins may be provided safely on shell surfaces for functional requirements up to $a^{\prime} / a=0.2$.

4.1.2. Effect of Boundary Conditions. The boundary conditions have been divided into four groups, so that the 
TABLe 7: Values of " $r$ ” for 0/90/0/90 hypar shells.

\begin{tabular}{|c|c|c|c|c|c|c|c|c|}
\hline \multirow{2}{*}{ Edge condition } & \multirow{2}{*}{$\bar{y}$} & \multicolumn{7}{|c|}{$\bar{x}$} \\
\hline & & 0.2 & 0.3 & 0.4 & 0.5 & 0.6 & 0.7 & 0.8 \\
\hline \multirow{7}{*}{ CCCC } & 0.2 & 97.52 & 98.19 & 99.14 & 99.69 & 99.12 & 98.17 & 97.49 \\
\hline & 0.3 & 98.23 & 98.83 & 99.51 & 99.87 & 99.51 & 98.81 & 98.22 \\
\hline & 0.4 & 99.25 & 99.61 & 99.86 & 99.96 & 99.86 & 99.6 & 99.23 \\
\hline & 0.5 & 99.86 & 100.03 & 100.03 & 100 & 100.03 & 100.03 & 99.86 \\
\hline & 0.6 & 99.23 & 99.6 & 99.86 & 99.97 & 99.86 & 99.61 & 99.25 \\
\hline & 0.7 & 98.22 & 98.81 & 99.51 & 99.86 & 99.51 & 98.83 & 98.23 \\
\hline & 0.8 & 97.49 & 98.16 & 99.09 & 99.68 & 99.1 & 98.16 & 97.51 \\
\hline \multirow{7}{*}{ CSCC } & 0.2 & 99.53 & 99.69 & 100.03 & 100.24 & 100.03 & 99.68 & 99.47 \\
\hline & 0.3 & 100.24 & 100.15 & 100.25 & 100.35 & 100.26 & 100.16 & 100.21 \\
\hline & 0.4 & 100.09 & 99.84 & 100 & 100.19 & 100.02 & 99.86 & 100.1 \\
\hline & 0.5 & 97.94 & 98.62 & 99.33 & 100 & 99.34 & 98.63 & 98.79 \\
\hline & 0.6 & 97.34 & 97.15 & 98.3 & 99.78 & 98.29 & 97.16 & 97.35 \\
\hline & 0.7 & 96.37 & 95.99 & 96.98 & 99.42 & 96.98 & 96 & 96.38 \\
\hline & 0.8 & 95.87 & 95.29 & 95.69 & 96.68 & 95.7 & 95.3 & 95.89 \\
\hline \multirow{7}{*}{ CCSC } & 0.2 & 96.21 & 96.77 & 97.75 & 99.07 & 100.12 & 100.13 & 99.48 \\
\hline & 0.3 & 95.57 & 96.35 & 97.51 & 98.83 & 99.83 & 100.09 & 99.72 \\
\hline & 0.4 & 95.66 & 97.17 & 98.52 & 99.42 & 99.96 & 100.24 & 100.13 \\
\hline & 0.5 & 95.95 & 99.59 & 99.9 & 100 & 100.13 & 100.35 & 100.38 \\
\hline & 0.6 & 95.58 & 97.08 & 98.46 & 99.39 & 99.96 & 100.24 & 100.13 \\
\hline & 0.7 & 95.52 & 96.3 & 97.46 & 98.8 & 99.83 & 100.1 & 99.72 \\
\hline & 0.8 & 96.21 & 96.75 & 97.68 & 98.99 & 100.1 & 100.12 & 99.49 \\
\hline \multirow{7}{*}{ CCCS } & 0.2 & 95.89 & 95.31 & 95.71 & 96.64 & 95.67 & 95.29 & 95.87 \\
\hline & 0.3 & 96.38 & 96 & 96.97 & 99.41 & 96.96 & 95.99 & 96.37 \\
\hline & 0.4 & 97.35 & 97.16 & 98.29 & 99.78 & 98.29 & 97.15 & 97.34 \\
\hline & 0.5 & 98.79 & 98.63 & 99.34 & 100 & 99.33 & 98.62 & 98.78 \\
\hline & 0.6 & 100.1 & 99.86 & 100.02 & 100.19 & 100 & 99.84 & 100.08 \\
\hline & 0.7 & 100.21 & 100.16 & 100.26 & 100.35 & 100.25 & 100.15 & 100.21 \\
\hline & 0.8 & 99.32 & 99.49 & 99.83 & 100.05 & 99.83 & 99.47 & 99.31 \\
\hline \multirow{7}{*}{ CSSC } & 0.2 & 98.79 & 98.82 & 99.2 & 99.86 & 100.55 & 100.89 & 100.79 \\
\hline & 0.3 & 98.95 & 99.27 & 99.66 & 100.08 & 100.48 & 100.8 & 100.95 \\
\hline & 0.4 & 98.27 & 100.33 & 100.3 & 100.38 & 100.43 & 100.46 & 100.57 \\
\hline & 0.5 & 96.25 & 97.59 & 98.9 & 100 & 100.32 & 99.93 & 99.75 \\
\hline & 0.6 & 96.09 & 96.3 & 97.29 & 99.15 & 100.22 & 99.4 & 99.01 \\
\hline & 0.7 & 96.62 & 96.19 & 96.67 & 98.31 & 100.17 & 98.95 & 98.66 \\
\hline & 0.8 & 97.57 & 96.83 & 96.72 & 97.23 & 98.56 & 98.61 & 98.7 \\
\hline \multirow{7}{*}{ CCSS } & 0.2 & 97.54 & 96.8 & 96.73 & 97.24 & 98.51 & 98.56 & 98.64 \\
\hline & 0.3 & 96.61 & 96.18 & 96.66 & 98.3 & 100.13 & 98.91 & 98.62 \\
\hline & 0.4 & 96.14 & 96.34 & 97.32 & 99.15 & 100.2 & 99.37 & 98.99 \\
\hline & 0.5 & 96.32 & 97.69 & 98.95 & 100 & 100.29 & 99.9 & 99.73 \\
\hline & 0.6 & 98.28 & 100.3 & 100.27 & 100.34 & 100.38 & 100.41 & 100.53 \\
\hline & 0.7 & 98.84 & 99.19 & 99.6 & 100.03 & 100.44 & 100.76 & 100.91 \\
\hline & 0.8 & 98.65 & 98.67 & 98.92 & 99.56 & 100.32 & 100.69 & 100.63 \\
\hline \multirow{7}{*}{ CSCS } & 0.2 & 86.53 & 86.51 & 86.95 & 86.16 & 86.97 & 86.49 & 86.48 \\
\hline & 0.3 & 92.9 & 92.77 & 92.84 & 92.87 & 92.84 & 92.75 & 92.84 \\
\hline & 0.4 & 96.52 & 96.4 & 97.17 & 97.7 & 97.17 & 96.38 & 96.47 \\
\hline & 0.5 & 97.17 & 97.41 & 98.85 & 100 & 98.84 & 97.41 & 97.17 \\
\hline & 0.6 & 96.47 & 96.39 & 97.17 & 97.7 & 97.17 & 96.4 & 96.5 \\
\hline & 0.7 & 92.84 & 92.75 & 92.84 & 92.88 & 92.84 & 92.77 & 92.9 \\
\hline & 0.8 & 86.17 & 86.18 & 86.66 & 87.02 & 86.73 & 86.33 & 86.33 \\
\hline
\end{tabular}


Table 7: Continued.

\begin{tabular}{|c|c|c|c|c|c|c|c|c|}
\hline \multirow{2}{*}{ Edge condition } & \multirow{2}{*}{$\bar{y}$} & \multicolumn{7}{|c|}{$\bar{x}$} \\
\hline & & 0.2 & 0.3 & 0.4 & 0.5 & 0.6 & 0.7 & 0.8 \\
\hline \multirow{7}{*}{ SCSC } & 0.2 & 86.38 & 92.89 & 97.14 & 98.25 & 97.12 & 92.87 & 86.36 \\
\hline & 0.3 & 86.43 & 92.92 & 96.97 & 98.23 & 96.93 & 92.87 & 85.96 \\
\hline & 0.4 & 86.9 & 92.92 & 97.45 & 99.25 & 97.39 & 92.87 & 86.84 \\
\hline & 0.5 & 87.13 & 92.85 & 97.71 & 100 & 97.71 & 92.85 & 87.13 \\
\hline & 0.6 & 86.84 & 92.87 & 97.39 & 99.25 & 97.45 & 92.92 & 86.9 \\
\hline & 0.7 & 86.39 & 92.87 & 96.93 & 98.22 & 96.95 & 92.92 & 86.43 \\
\hline & 0.8 & 86.27 & 92.76 & 97.09 & 98.14 & 97.05 & 92.8 & 86.31 \\
\hline \multirow{7}{*}{ CSSS } & 0.2 & 87.55 & 87.4 & 87.57 & 88.03 & 88.73 & 89.14 & 88.85 \\
\hline & 0.3 & 94.37 & 94.44 & 94.06 & 94.01 & 95.18 & 96.65 & 96.62 \\
\hline & 0.4 & 98.85 & 98.84 & 98.33 & 98.33 & 99.99 & 101.94 & 101.87 \\
\hline & 0.5 & 100.37 & 100.28 & 99.82 & 100 & 101.89 & 103.9 & 103.68 \\
\hline & 0.6 & 98.76 & 98.77 & 98.29 & 98.31 & 99.99 & 101.94 & 101.87 \\
\hline & 0.7 & 94.28 & 94.37 & 94.02 & 93.98 & 95.16 & 96.63 & 96.59 \\
\hline & 0.8 & 87.17 & 87.1 & 87.29 & 87.74 & 88.4 & 88.85 & 88.6 \\
\hline \multirow{7}{*}{ SSSC } & 0.2 & 89.01 & 96.86 & 102.03 & 103.78 & 102.03 & 96.86 & 88.99 \\
\hline & 0.3 & 89.2 & 96.84 & 102.06 & 103.95 & 102.06 & 96.82 & 89.16 \\
\hline & 0.4 & 88.7 & 95.26 & 100.02 & 101.88 & 100.03 & 95.26 & 88.7 \\
\hline & 0.5 & 87.94 & 94.02 & 98.32 & 100 & 98.39 & 94.1 & 88 \\
\hline & 0.6 & 87.47 & 94.07 & 98.36 & 99.88 & 98.44 & 94.18 & 87.55 \\
\hline & 0.7 & 87.29 & 94.47 & 98.9 & 100.4 & 98.98 & 94.56 & 87.38 \\
\hline & 0.8 & 87.34 & 94.26 & 98.78 & 100.33 & 98.84 & 94.35 & 87.42 \\
\hline \multirow{7}{*}{ SSCS } & 0.2 & 88.83 & 89.09 & 88.68 & 88 & 87.53 & 87.34 & 87.45 \\
\hline & 0.3 & 96.58 & 96.62 & 95.15 & 93.97 & 94.01 & 94.37 & 94.27 \\
\hline & 0.4 & 101.85 & 101.94 & 99.98 & 98.3 & 98.27 & 98.77 & 98.78 \\
\hline & 0.5 & 103.67 & 103.9 & 101.89 & 100 & 99.82 & 100.28 & 100.36 \\
\hline & 0.6 & 101.87 & 101.94 & 99.98 & 98.33 & 98.32 & 98.83 & 98.83 \\
\hline & 0.7 & 96.61 & 96.65 & 95.17 & 94 & 94.05 & 94.44 & 94.37 \\
\hline & 0.8 & 88.43 & 88.7 & 88.33 & 87.77 & 87.26 & 87.21 & 87.22 \\
\hline \multirow{7}{*}{ SSSS } & 0.2 & 83.79 & 86.96 & 87.85 & 88.06 & 87.93 & 87.06 & 83.88 \\
\hline & 0.3 & 87.24 & 93.04 & 94.61 & 94.75 & 94.7 & 93.12 & 87.28 \\
\hline & 0.4 & 88.2 & 94.89 & 98.09 & 98.78 & 98.2 & 94.94 & 88.2 \\
\hline & 0.5 & 88.38 & 95.08 & 99.09 & 100 & 99.09 & 95.08 & 88.38 \\
\hline & 0.6 & 88.21 & 94.95 & 98.2 & 98.78 & 98.09 & 94.89 & 88.2 \\
\hline & 0.7 & 87.28 & 93.12 & 94.68 & 94.75 & 94.61 & 93.04 & 87.24 \\
\hline & 0.8 & 83.72 & 86.9 & 87.65 & 87.76 & 87.44 & 86.79 & 83.43 \\
\hline
\end{tabular}

$a / b=1, a / h=100, a^{\prime} / b^{\prime}=1, c / a=0.2 ; E_{11} / E_{22}=25, G_{23}=0.2 E_{22}, G_{13}=G_{12}=0.5 E_{22}, \nu_{12}=\nu_{21}=0.25, b_{\text {st }} / h=1, d_{\text {st }} / h=2$. Each stiffener has a single lamina with fibres along its length.

combinations in a particular group have equal number of boundary reactions. The groups are of the following forms:

Group I contains CCCC shells.

Group II contains CSCC, CCSC, and CCCS shells.

Group III contains CSSC, CCSS, CSCS, and SCSC shells.

Group IV contains SSSS shells.
As evident from Figures 5 and 6, fundamental frequencies of members belonging to different boundary combinations may be regrouped according to performance.

According to the values of $(\bar{\omega})$, Group III may be subdivided into Group IIIa and Group IIIb for both 0/90/0/90 and $+45 /-45 /+45 /-45$ shells.

Group I contains CCCC shells.

Group II contains CSCC, CCSC, and CCCS shells.

Group IIIa contains CSSC, CCSS shells. 
TABLE 8: Values of " $r$ " for $+45 /-45 /+45 /-45$ hypar shells.

\begin{tabular}{|c|c|c|c|c|c|c|c|c|}
\hline \multirow{2}{*}{ Edge condition } & \multirow{2}{*}{$\bar{y}$} & \multicolumn{7}{|c|}{$\bar{x}$} \\
\hline & & 0.2 & 0.3 & 0.4 & 0.5 & 0.6 & 0.7 & 0.8 \\
\hline \multirow{7}{*}{ CCCC } & 0.2 & 75.5 & 77.52 & 79.62 & 81.91 & 79.62 & 77.53 & 75.48 \\
\hline & 0.3 & 77.73 & 83.09 & 88.13 & 90.22 & 87.48 & 83.1 & 77.73 \\
\hline & 0.4 & 79.88 & 88.13 & 94.67 & 97.1 & 94.66 & 87.7 & 79.88 \\
\hline & 0.5 & 81.64 & 90.22 & 96.18 & 100 & 96.18 & 89.43 & 81.65 \\
\hline & 0.6 & 79.88 & 87.48 & 94.67 & 97.1 & 94.67 & 87.56 & 79.88 \\
\hline & 0.7 & 77.73 & 83.1 & 87.78 & 90.23 & 87.45 & 83.09 & 77.73 \\
\hline & 0.8 & 75.23 & 77.24 & 79.46 & 81.91 & 79.59 & 77.26 & 75.22 \\
\hline \multirow{7}{*}{ CSCC } & 0.2 & 107.37 & 111.09 & 113.43 & 114.35 & 113.44 & 111.12 & 107.33 \\
\hline & 0.3 & 109.36 & 116.53 & 120.39 & 120.22 & 120.33 & 116.71 & 109.43 \\
\hline & 0.4 & 110.05 & 113.46 & 112.76 & 111.31 & 112.73 & 113.62 & 110.23 \\
\hline & 0.5 & 106.26 & 107.25 & 102.28 & 100 & 102.23 & 107.25 & 106.1 \\
\hline & 0.6 & 103.13 & 100.64 & 95.53 & 93.26 & 95.47 & 100.66 & 102.59 \\
\hline & 0.7 & 98.44 & 94.11 & 90.94 & 89 & 90.86 & 94.96 & 97.47 \\
\hline & 0.8 & 92.85 & 89.98 & 87.17 & 85.77 & 87.11 & 90.07 & 92.03 \\
\hline \multirow{7}{*}{ CCSC } & 0.2 & 92.25 & 97.51 & 102.65 & 106.18 & 110.36 & 109.26 & 107.52 \\
\hline & 0.3 & 90.31 & 95.06 & 100.71 & 107.15 & 113.38 & 116.61 & 111.43 \\
\hline & 0.4 & 87.39 & 90.93 & 95.43 & 102.23 & 112.88 & 120.74 & 113.94 \\
\hline & 0.5 & 86.01 & 88.94 & 93.11 & 100 & 111.51 & 120.59 & 114.85 \\
\hline & 0.6 & 87.39 & 90.93 & 95.43 & 102.23 & 112.88 & 120.71 & 113.96 \\
\hline & 0.7 & 90.31 & 95.07 & 100.71 & 107.15 & 113.39 & 116.77 & 111.39 \\
\hline & 0.8 & 92.22 & 97.4 & 102.31 & 106.04 & 110.01 & 109.17 & 107.57 \\
\hline \multirow{7}{*}{ CCCS } & 0.2 & 91.86 & 90.02 & 87.14 & 85.78 & 87.14 & 90.02 & 91.86 \\
\hline & 0.3 & 97.09 & 94.85 & 90.89 & 89 & 90.89 & 94.85 & 97.09 \\
\hline & 0.4 & 102.26 & 100.62 & 95.5 & 93.27 & 95.5 & 100.62 & 102.25 \\
\hline & 0.5 & 105.99 & 107.28 & 102.26 & 100 & 102.26 & 107.28 & 105.93 \\
\hline & 0.6 & 110.5 & 113.49 & 112.73 & 111.27 & 112.72 & 113.49 & 110.06 \\
\hline & 0.7 & 109.37 & 116.56 & 120.35 & 120.21 & 120.35 & 116.58 & 109.37 \\
\hline & 0.8 & 106.23 & 109.95 & 112.53 & 113.65 & 112.87 & 110.26 & 106.66 \\
\hline \multirow{7}{*}{ CSSC } & 0.2 & 95.93 & 100.5 & 103.22 & 102.74 & 101.52 & 100.22 & 97.64 \\
\hline & 0.3 & 93.28 & 97.34 & 101.01 & 102.67 & 103.21 & 102.67 & 100.37 \\
\hline & 0.4 & 90.61 & 94.01 & 97.93 & 100.97 & 102.56 & 103.17 & 101.65 \\
\hline & 0.5 & 91.13 & 94.4 & 98.11 & 100 & 100.55 & 102.33 & 102.63 \\
\hline & 0.6 & 95.01 & 98.53 & 100.05 & 97.71 & 97.28 & 100.34 & 102.78 \\
\hline & 0.7 & 99.07 & 101.19 & 98.19 & 93.94 & 93.32 & 96.59 & 99.91 \\
\hline & 0.8 & 96.67 & 98.42 & 94.33 & 90.33 & 89.66 & 92.33 & 95.22 \\
\hline \multirow{7}{*}{ CCSS } & 0.2 & 97.17 & 98.62 & 94.38 & 90.41 & 89.83 & 92.61 & 95.51 \\
\hline & 0.3 & 99.04 & 101.42 & 98.17 & 93.99 & 93.49 & 96.79 & 100.11 \\
\hline & 0.4 & 95 & 98.7 & 100.12 & 97.75 & 97.43 & 100.53 & 102.97 \\
\hline & 0.5 & 91.08 & 94.55 & 98.15 & 100 & 100.66 & 102.49 & 102.78 \\
\hline & 0.6 & 90.55 & 94.13 & 97.97 & 101 & 102.65 & 103.29 & 101.75 \\
\hline & 0.7 & 93.3 & 97.5 & 101.13 & 102.8 & 103.35 & 102.81 & 100.5 \\
\hline & 0.8 & 95.63 & 100.33 & 103.41 & 102.77 & 101.64 & 100 & 97.48 \\
\hline \multirow{7}{*}{ CSCS } & 0.2 & 95.87 & 96.13 & 94.92 & 94.15 & 94.92 & 96.13 & 95.83 \\
\hline & 0.3 & 103.42 & 104.06 & 100.92 & 98.89 & 100.92 & 104.06 & 103.42 \\
\hline & 0.4 & 103.08 & 104.22 & 101.8 & 99.99 & 101.8 & 104.22 & 103.08 \\
\hline & 0.5 & 102.11 & 103.48 & 101.55 & 100 & 101.55 & 103.48 & 102.11 \\
\hline & 0.6 & 103.08 & 104.23 & 101.8 & 100 & 101.8 & 104.22 & 103.08 \\
\hline & 0.7 & 103.42 & 104.06 & 100.92 & 98.89 & 100.92 & 104.06 & 103.42 \\
\hline & 0.8 & 94.95 & 95.31 & 94.23 & 93.78 & 94.29 & 95.6 & 95.17 \\
\hline
\end{tabular}


TABle 8: Continued.

\begin{tabular}{|c|c|c|c|c|c|c|c|c|}
\hline \multirow{2}{*}{ Edge condition } & \multirow{2}{*}{$\bar{y}$} & \multicolumn{7}{|c|}{$\bar{x}$} \\
\hline & & 0.2 & 0.3 & 0.4 & 0.5 & 0.6 & 0.7 & 0.8 \\
\hline \multirow{7}{*}{ SCSC } & 0.2 & 96.22 & 103.6 & 103.18 & 102.26 & 103.18 & 103.6 & 96.22 \\
\hline & 0.3 & 96.53 & 104.15 & 104.36 & 103.67 & 104.36 & 104.15 & 96.53 \\
\hline & 0.4 & 95.31 & 100.98 & 101.85 & 101.68 & 101.85 & 100.98 & 95.31 \\
\hline & 0.5 & 94.52 & 98.92 & 99.94 & 100 & 99.94 & 98.93 & 94.52 \\
\hline & 0.6 & 95.31 & 100.98 & 101.85 & 101.68 & 101.85 & 100.98 & 95.31 \\
\hline & 0.7 & 96.53 & 104.15 & 104.36 & 103.67 & 104.36 & 104.15 & 96.53 \\
\hline & 0.8 & 96.23 & 103.59 & 103.13 & 102.19 & 103.13 & 105.58 & 96.22 \\
\hline \multirow{7}{*}{ CSSS } & 0.2 & 94.97 & 96.22 & 94.35 & 91.61 & 90.5 & 91.12 & 90.97 \\
\hline & 0.3 & 103.71 & 105.89 & 102.58 & 97.88 & 96.51 & 98.02 & 98.03 \\
\hline & 0.4 & 104.04 & 106.17 & 103.76 & 99.83 & 98.56 & 94.14 & 99.79 \\
\hline & 0.5 & 103.07 & 105.12 & 103.26 & 100 & 98.84 & 99.89 & 99.89 \\
\hline & 0.6 & 104.04 & 106.17 & 103.76 & 99.83 & 98.56 & 99.78 & 99.79 \\
\hline & 0.7 & 103.71 & 105.89 & 102.58 & 97.89 & 96.51 & 98.03 & 98.03 \\
\hline & 0.8 & 94.35 & 95.69 & 93.98 & 91.17 & 90.05 & 90.5 & 90.42 \\
\hline \multirow{7}{*}{ SSSC } & 0.2 & 90.77 & 97.71 & 99.57 & 99.72 & 99.58 & 97.7 & 90.77 \\
\hline & 0.3 & 91.11 & 97.83 & 99.65 & 99.8 & 99.65 & 97.83 & 91.11 \\
\hline & 0.4 & 90.67 & 96.5 & 98.5 & 98.79 & 98.5 & 96.51 & 90.67 \\
\hline & 0.5 & 91.95 & 98 & 99.83 & 100 & 99.83 & 98 & 91.95 \\
\hline & 0.6 & 94.82 & 102.81 & 103.94 & 103.44 & 103.94 & 102.81 & 94.81 \\
\hline & 0.7 & 96.72 & 106.2 & 106.42 & 105.32 & 106.42 & 106.2 & 96.72 \\
\hline & 0.8 & 95.38 & 104.11 & 104.24 & 103.18 & 104.22 & 104.09 & 95.38 \\
\hline \multirow{7}{*}{ SSCS } & 0.2 & 90.97 & 91.14 & 90.5 & 91.61 & 94.35 & 96.23 & 94.99 \\
\hline & 0.3 & 98.03 & 98.03 & 96.51 & 97.88 & 102.58 & 105.89 & 103.71 \\
\hline & 0.4 & 95.29 & 99.78 & 98.56 & 99.83 & 103.76 & 106.17 & 104.04 \\
\hline & 0.5 & 99.89 & 99.89 & 98.84 & 100 & 103.26 & 105.12 & 103.07 \\
\hline & 0.6 & 99.81 & 99.79 & 98.56 & 99.83 & 103.76 & 106.17 & 104.04 \\
\hline & 0.7 & 98.03 & 98.03 & 96.51 & 97.89 & 102.59 & 105.89 & 103.71 \\
\hline & 0.8 & 89.91 & 90.07 & 89.62 & 91.29 & 93.56 & 95.74 & 94.07 \\
\hline \multirow{7}{*}{ SSSS } & 0.2 & 90.91 & 91.7 & 89.71 & 88.65 & 89.71 & 91.7 & 90.91 \\
\hline & 0.3 & 91.48 & 99.37 & 97.5 & 95.99 & 97.5 & 99.37 & 91.48 \\
\hline & 0.4 & 89.64 & 97.39 & 100.37 & 99.5 & 100.37 & 97.39 & 89.64 \\
\hline & 0.5 & 88.62 & 95.93 & 99.42 & 100 & 99.42 & 95.93 & 88.62 \\
\hline & 0.6 & 89.64 & 97.39 & 100.37 & 99.49 & 100.37 & 97.39 & 89.64 \\
\hline & 0.7 & 91.48 & 99.37 & 97.51 & 95.99 & 97.51 & 99.37 & 91.48 \\
\hline & 0.8 & 90.69 & 91.02 & 89.15 & 88.3 & 89.06 & 91.21 & 90.3 \\
\hline
\end{tabular}

$a / b=1, a / h=100, a^{\prime} / b^{\prime}=1, c / a=0.2 ; E_{11} / E_{22}=25, G_{23}=0.2 E_{22}, G_{13}=G_{12}=0.5 E_{22}, v_{12}=v_{21}=0.25, b_{\mathrm{st}} / h=1, d_{\mathrm{st}} / h=2$. Each stiffener has a single lamina with fibres along its length.

Group IIIb contains CSCS and SCSC shells.

Group IV contains SSSS shells.

This observation indicates that the impact of number of boundary constraints is far more important than their arrangement. But the impact of arrangement of boundary constraints is not negligible in case of the shells which have two clamped edges. It is found that when two adjacent edges are clamped, the frequency attains greater value than when two alternate edges are clamped.
The frequencies are further studied and marks are given to the options of clamping the edges of a simply supported shell in order to gradually improve performances. Tables 5 and 6 furnish such clamping options for cross-ply and angle-ply shells, respectively. The scale is chosen like this, 0 is assigned to a simply supported shell and 100 to a clamped shell. These marks are furnished for cutouts with $a^{\prime} / a=0.2$. These tables will help a practicing engineer. If one takes the frequency of a clamped shell as upper limit and that of the simply supported as lower limit, one can easily realize the efficiency of a particular boundary condition. 


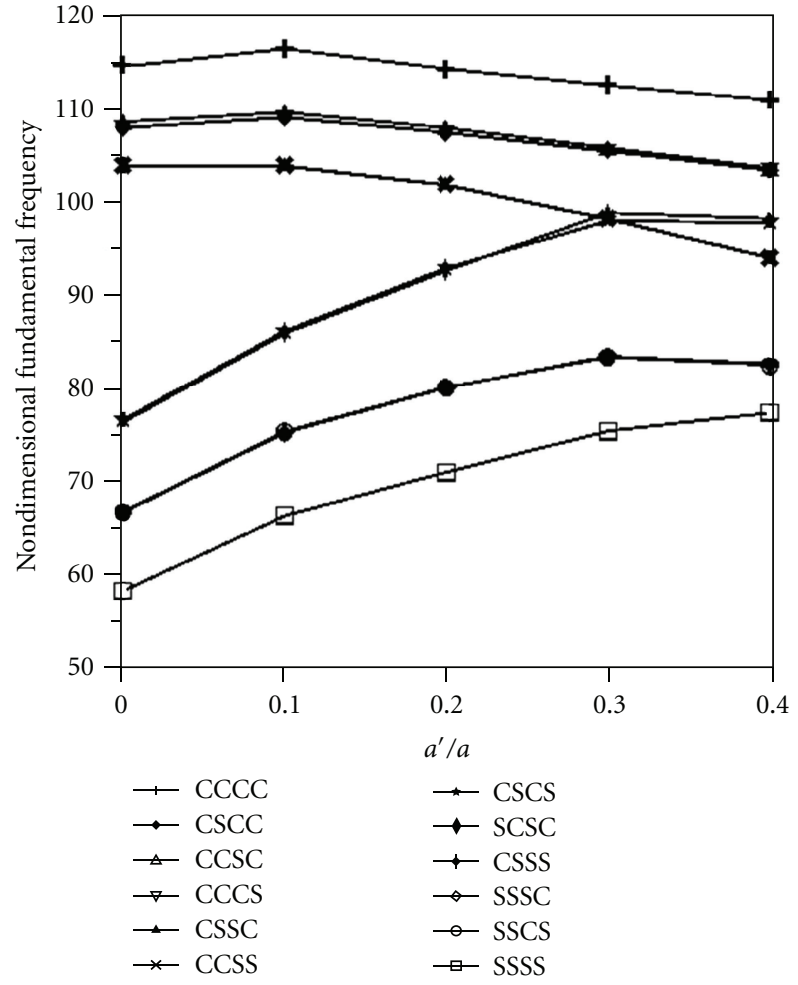

Figure 5: Values of non-dimensional fundamental frequency $(\bar{\omega})$ of 0/90/0/90 stiffened hypar shell with cutout for different sizes of central cutout and boundary conditions; $a / b=1, a / h=100$, $a^{\prime} / b^{\prime}=1, c / a=0.2 ; E_{11} / E_{22}=25, G_{23}=0.2 E_{22}, G_{13}=G_{12}=$ $0.5 E_{22}, v_{12}=v_{21}=0.25, b_{\mathrm{st}} / h=1, d_{\mathrm{st}} / h=2$. Each stiffener has a single lamina with fibres along its length.

\subsection{Effect of Eccentricity of Cutout Position on Fundamen-} tal Frequency. To study the effect of cutout positions on fundamental frequencies, results are obtained for different locations of a cutout with $a^{\prime} / a=0.2$. Each of the nondimensional coordinates of the cutout centre $(\bar{x}=x / a, \bar{y}=$ $y / a)$ is varied from 0.2 to 0.8 along both the plan directions so that the distance of a cutout margin from the shell boundary is not less than one tenth of the plan dimension of the shell. The study is carried out for all the twelve boundary conditions for both 0/90/0/90 and +45/-45/+45/-45 hypar shells. The ratio of the fundamental frequency of a shell with an eccentric puncture to that of a shell with concentric puncture (obtainable from Figures 5 and 6) expressed in percentage is denoted by $r$. Tables 7 and 8 contain the value of $r$ for 0/90/0/90 and $+45 /-45 /+45 /-45$ hypar shells.

It may be seen that the fundamental frequency is maximum when cutout is along the centre line of the shell. This is true for cross-ply shells with four edges simply supported or clamped. In case of clamped angle ply shells, similar trend is observed, but in case of a simply supported angle ply shells, the fundamental frequency is maximum when the cutout centre is along the diagonal. For the shells which have one edge simply supported and others clamped the fundamental frequency increases towards the simply supported edge. This observation is true for cross ply as well

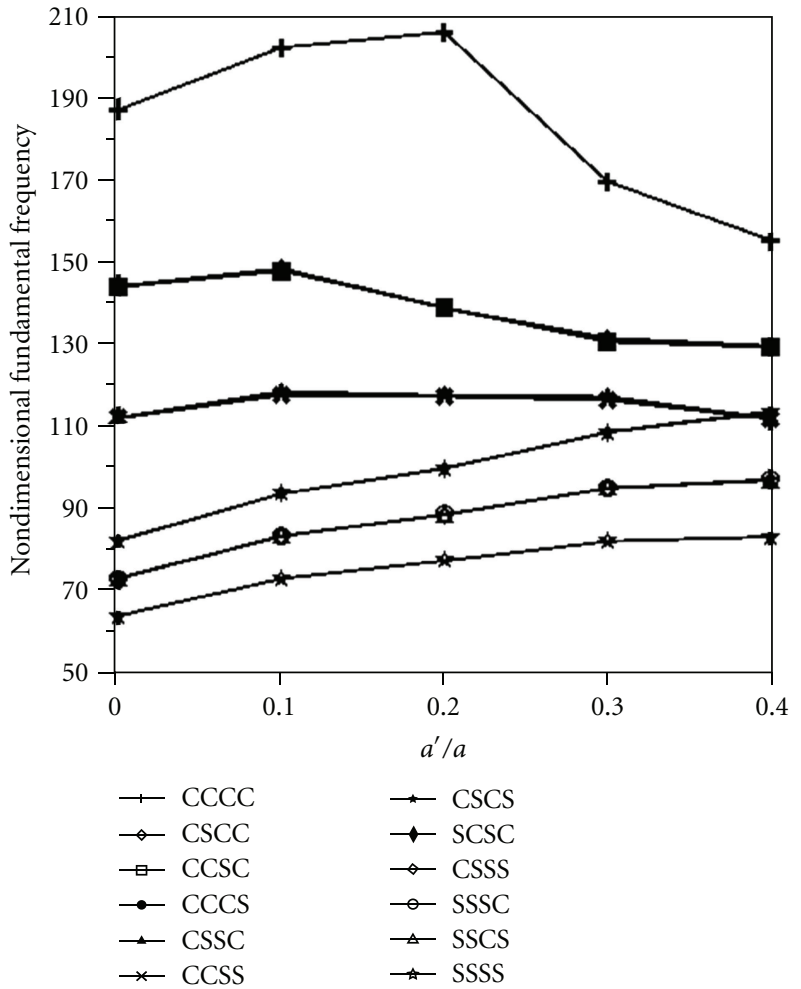

FIGURE 6: Values of non-dimensional fundamental frequency $(\bar{\omega})$ of $+45 /-45 /+45 /-45$ stiffened hypar shell with cutout for different sizes of central cutout and boundary conditions; $a / b=1, a / h=$ $100, a^{\prime} / b^{\prime}=1, c / a=0.2 ; E_{11} / E_{22}=25, G_{23}=0.2 E_{22}, G_{13}=G_{12}=$ $0.5 E_{22}, \nu_{12}=v_{21}=0.25, b_{\text {st }} / h=1, d_{\text {st }} / h=2$. Each stiffener has a single lamina with fibres along its length.

as angle ply shells. For the cross ply shells which have two opposite edges clamped and others opposite edges simply supported, the shell become stiffer when the cutout is placed along the centre line of the shell. But in case of angle ply shell with same boundary condition, the fundamental frequency of shell increases when the cutout centre is towards the clamped edges. It is further noticed that the shells with three edges simply supported and other clamped fundamental frequency is maximum when cutout centre is along the line which is equidistant from two simply supported edges. Along the other direction, when the cutout centre shifts towards the simply supported edge, which is opposite to be clamped edge, the shell becomes stiffer. But reverse is the case for angle ply shells. Here, the shifting of cutout centre towards the simply supported edges makes the shell flexible.

Tables 9 and 10 provide the maximum values of $r$ together with the corresponding values of $\bar{x}$ and $\bar{y}$ indicating the positions of the cutouts. These tables further specify rectangular zones within which the centre of the cutout may be varied so that the value of $r$ is always greater than or equal to 95 and less than or equal to 90 (resp.). It is to be noted that the cutout centre may be placed at some points beyond the zones indicated in Tables 9 and 10 to obtain similar values of $r$, but only zones rectangular in plan are identified in the tables. These tables will enable practicing engineers to get an 
TABLE 9: Maximum values of $r$ with corresponding coordinates of cutout centres and zones where $r \leq 90$ and $r \geq 95$ for $0 / 90 / 0 / 90$ hypar shells.

\begin{tabular}{|c|c|c|c|c|}
\hline Boundary Condition & Maximum values of $r$ & Coordinate of cutout centre & $\begin{array}{l}\text { Area in which the value of } \\
\qquad r \leq 90\end{array}$ & $\begin{array}{l}\text { Area in which the value } \\
\qquad r \geq 95\end{array}$ \\
\hline \multirow{2}{*}{ CCCC } & \multirow{2}{*}{100.03} & \multirow{2}{*}{$\begin{array}{l}(0.3,0.5),(0.4,0.5) \\
(0.6,0.5),(0.7,0.5)\end{array}$} & \multirow{2}{*}{ Nil } & $0.2 \leq \bar{x} \leq 0.8$ \\
\hline & & & & $0.2 \leq \bar{y}_{\leq} \leq 0.8$ \\
\hline \multirow{2}{*}{ CSCC } & \multirow{2}{*}{100.35} & \multirow{2}{*}{$(0.5,0.3)$} & \multirow{2}{*}{ Nil } & $0.2 \leq \bar{x} \leq 0.8$ \\
\hline & & & & $0.2 \leq \bar{y}_{\leq} 0.8$ \\
\hline \multirow{2}{*}{ CCSC } & \multirow{2}{*}{100.38} & \multirow{2}{*}{$(0.8,0.5)$} & \multirow{2}{*}{ Nil } & $0.2 \leq \bar{x} \leq 0.8$ \\
\hline & & & & $0.2 \leq \bar{y} \leq 0.8$ \\
\hline \multirow{2}{*}{ CCCS } & \multirow{2}{*}{100.35} & \multirow{2}{*}{$(0.5,0.7)$} & \multirow{2}{*}{ Nil } & $0.2 \leq \bar{x} \leq 0.8$ \\
\hline & & & & $0.2 \leq \bar{y}_{\leq} \leq 0.8$ \\
\hline \multirow{2}{*}{ CSSC } & \multirow{2}{*}{100.95} & \multirow{2}{*}{$(0.8,0.3)$} & \multirow{2}{*}{ Nil } & $0.2 \leq \bar{x} \leq 0.8$ \\
\hline & & & & $0.2 \leq \bar{y}_{\leq} \leq 0.8$ \\
\hline \multirow{2}{*}{ CCSS } & \multirow{2}{*}{100.91} & \multirow{2}{*}{$(0.8,0.6)$} & \multirow{2}{*}{ Nil } & $0.2 \leq \bar{x} \leq 0.8$ \\
\hline & & & & $0.2 \leq \bar{y} \leq 0.8$ \\
\hline \multirow{2}{*}{ CSCS } & \multirow{2}{*}{100.00} & \multirow{2}{*}{$(0.5,0.5)$} & $0.2 \leq \bar{x} \leq 0.8, \bar{y}=0.2$ & $0.2 \leq \bar{x} \leq 0.8$ \\
\hline & & & $0.2 \leq \bar{x} \leq 0.8, \bar{y}=0.8$ & $0.4 \leq \bar{y}_{\leq} \leq 0.6$ \\
\hline \multirow{2}{*}{ SCSC } & \multirow{2}{*}{100.00} & \multirow{2}{*}{$(0.5,0.5)$} & $\bar{x}=0.2,0.2 \leq \bar{y}_{\leq} \leq 0.8$ & $0.4 \leq \bar{x} \leq 0.6$ \\
\hline & & & $\bar{x}=0.8,0.2 \leq \bar{y}_{\leq} 0.8$ & $0.2 \leq \bar{y}_{\leq} \leq 0.8$ \\
\hline \multirow{2}{*}{ CSSS } & \multirow{2}{*}{103.90} & \multirow{2}{*}{$(0.7,0.5)$} & $0.2 \leq \bar{x} \leq 0.8, \bar{y}=0.2$ & $0.2 \leq \bar{x} \leq 0.8$ \\
\hline & & & $0.2 \leq \bar{x} \leq 0.8, \bar{y}=0.8$ & $0.4 \leq \bar{y}_{\leq} \leq 0.6$ \\
\hline \multirow{2}{*}{ SSSC } & 10395 & $(0503)$ & $\bar{x}=0.2,0.2 \leq \bar{y}_{\leq} 0.8$ & $0.4 \leq \bar{x} \leq 0.6$ \\
\hline & 100.90 & $(0.5,0.5)$ & $\bar{x}=0.8,0.2 \leq \bar{y} \leq 0.8$ & $0.2 \leq \bar{y}_{\leq} \leq 0.8$ \\
\hline SSCS & 103.90 & $(0.3 .0 .5)$ & $0.2 \leq \bar{x} \leq 0.8, \bar{y}=0.2$ & $0.2 \leq \bar{x} \leq 0.8$ \\
\hline & 105.90 & $(0.5,0.5)$ & $0.2 \leq \bar{x} \leq 0.8, \bar{y}=0.8$ & $0.4 \leq \bar{y}_{\leq} \leq 0.6$ \\
\hline SSSS & 10000 & $(05.05)$ & $\bar{x}=0.2,0.2 \leq \bar{y} \leq 0.8$ & $0.4 \leq \bar{x} \leq 0.6$ \\
\hline 5555 & 100.00 & $(0.5,0.5)$ & $\bar{x}=0.8,0.2 \leq \bar{y} \leq 0.8$ & $0.4 \leq \bar{y}_{\leq} \leq 0.6$ \\
\hline
\end{tabular}

$a / b=1, a / h=100, a^{\prime} / b^{\prime}=1, c / a=0.2 ; E_{11} / E_{22}=25, G_{23}=0.2 E_{22}, G_{13}=G_{12}=0.5 E_{22}, v_{12}=v_{21}=0.25, b_{\mathrm{st}} / h=1, d_{\mathrm{st}} / h=2$. Each stiffener has a single lamina with fibres along its length.

idea of the maximum eccentricity of a cutout which can be permitted if the fundamental frequency of a concentrically punctured shell is not to suffer a drastic reduction in value.

\section{Conclusions}

From the present study, the following conclusions are drawn.

(1) The finite element code used here is suitable for analysing free vibration problems of stiffened hypar shell roofs with cutouts as this approach produces results in close agreement with those of the benchmark problems.

(2) Concentric cutouts may be provided safely on stiffened hypar shell surfaces for functional requirements up to $a^{\prime} / a=0.2$.

(3) The arrangement of boundary constraints along the four edges is far more important than their actual number as long as the free vibration stiffness is concerned.
(4) Fundamental frequency undergoes marked improvement when the edge is converted to clamped from simply supported condition.

(5) The relative free vibration performances of stiffened hypar shells for different combinations of edge conditions along the four sides are expected to be very useful in decision making for practicing engineers.

(6) The information regarding the behaviour of stiffened hypar shell with eccentric cutouts for wide range of eccentricity and boundary conditions may be used as design aids by structural engineers.

(7) As furnished, the specific zones within which the cutout centre may be varied such that the loss of fundamental frequency is within $5 \%$ with respect to a shell with concentric cutout also the specific zones which should be avoided (where the frequency decrease is greater than equal to $10 \%$ ) will help to make a decision regarding the eccentricity of the cutout centre that can be allowed. 
TABLE 10: Maximum values of $r$ with corresponding coordinates of cutout centres and zones where $r \leq 90$ and $r \geq 95$ for $+45 /-45 /+45 /-45$ hypar shells.

\begin{tabular}{|c|c|c|c|c|}
\hline Boundary Condition & Maximum values of $r$ & $\begin{array}{l}\text { Co-ordinate of cutout } \\
\text { centre }\end{array}$ & $\begin{array}{l}\text { Area in which the value of } \\
\qquad r \leq 90\end{array}$ & $\begin{array}{l}\text { Area in which the value } \\
\qquad r \geq 95\end{array}$ \\
\hline CCCC & 100.00 & $(0.5,0.5)$ & $\begin{array}{l}0.2 \leq \bar{x} \leq 0.3,0.2 \leq \bar{y} \leq 0.8 \\
0.7 \leq \bar{x} \leq 0.8,0.2 \leq \bar{y} \leq 0.8\end{array}$ & $\begin{array}{c}0.4 \leq \bar{x} \leq 0.6 \\
\bar{y}=0.5\end{array}$ \\
\hline CSCC & 120.39 & $(0.4,0.3)$ & $0.3 \leq \bar{x} \leq 0.6, \bar{y}=0.8$ & $\begin{array}{l}0.2 \leq \bar{x} \leq 0.8 \\
0.2 \leq \bar{y} \leq 0.6\end{array}$ \\
\hline CCSC & 120.74 & $(0.7,0.4)$ & $\bar{x}=0.2,0.4 \leq \bar{y}_{\leq} 0.6$ & $\begin{array}{l}0.5 \leq \bar{x} \leq 0.8 \\
0.2 \leq \bar{y} \leq 0.8\end{array}$ \\
\hline CCCS & 120.35 & $(0.4,0.7),(0.6,0.7)$ & $\begin{array}{c}0.4 \leq \bar{x} \leq 0.6 \\
\bar{y}=0.2\end{array}$ & $\begin{array}{l}0.2 \leq \bar{x} \leq 0.8 \\
0.4 \leq \bar{y} \leq 0.8\end{array}$ \\
\hline CSSC & 103.22 & $(0.4,0.2)$ & $\begin{array}{l}\bar{x}=0.6 \\
\bar{y}=0.8\end{array}$ & $\begin{array}{l}0.4 \leq \bar{x} \leq 0.8 \\
0.2 \leq \bar{y} \leq 0.6\end{array}$ \\
\hline CCSS & 103.35 & $(0.6,0.7)$ & $\begin{array}{l}\bar{x}=0.6 \\
\bar{y}=0.2\end{array}$ & $\begin{array}{l}0.2 \leq \bar{x} \leq 0.8 \\
0.4 \leq \bar{y} \leq 0.8\end{array}$ \\
\hline CSCS & 104.23 & $(0.3,0.6)$ & Nil & $\begin{array}{l}0.2 \leq \bar{x} \leq 0.8 \\
0.3 \leq \bar{y} \leq 0.7\end{array}$ \\
\hline SCSC & 105.58 & $(0.7,0.8)$ & Nil & $\begin{array}{l}0.3 \leq \bar{x} \leq 0.7 \\
0.2 \leq \bar{y} \leq 0.8\end{array}$ \\
\hline CSSS & 106.17 & $(0.3,0.4),(0.3,0.6)$ & Nil & $\begin{array}{l}0.2 \leq \bar{x} \leq 0.8 \\
0.3 \leq \bar{y} \leq 0.7\end{array}$ \\
\hline SSSC & 106.42 & $(0.4,0.7),(0.6,0.7)$ & Nil & $\begin{array}{l}0.3 \leq \bar{x} \leq 0.7 \\
0.2 \leq \bar{y} \leq 0.8\end{array}$ \\
\hline SSCS & 106.17 & $(0.7,0.4),(0.7,0.6)$ & $\begin{array}{c}0.2 \leq \bar{x} \leq 0.4 \\
\bar{y}=0.8\end{array}$ & $\begin{array}{l}0.2 \leq \bar{x} \leq 0.8 \\
0.3 \leq \bar{y} \leq 0.7\end{array}$ \\
\hline SSSS & 100.37 & $\begin{array}{l}(0.4,0.4),(0.6,0.4) \\
(0.4,0.6),(0.6,0.6)\end{array}$ & $\begin{array}{l}\bar{x}=0.2,0.4 \leq \bar{y}_{\leq} 0.6 \\
\bar{x}=0.8,0.4 \leq \bar{y} \leq 0.6\end{array}$ & $\begin{array}{l}0.3 \leq \bar{x} \leq 0.7 \\
0.3 \leq \bar{y} \leq 0.7\end{array}$ \\
\hline
\end{tabular}

$a / b=1, a / h=100, a^{\prime} / b^{\prime}=1, c / a=0.2 ; E_{11} / E_{22}=25, G_{23}=0.2 E_{22}, G_{13}=G_{12}=0.5 E_{22}, v_{12}=v_{21}=0.25, b_{\mathrm{st}} / h=1, d_{\mathrm{st}} / h=2$. Each stiffener has a single lamina with fibres along its length.

\section{Notations}

\begin{tabular}{|c|c|}
\hline$a, b:$ & Length and width of shell in plan \\
\hline$a^{\prime}, b^{\prime}:$ & Length and width of cutout in plan \\
\hline$b_{s t}:$ & Width of stiffener in general \\
\hline$b_{s x}, b_{s y}:$ & $\begin{array}{l}\text { Width of } X \text { and } Y \text { stiffeners, } \\
\text { respectively }\end{array}$ \\
\hline$B_{s x}, B_{s y}:$ & $\begin{array}{l}\text { Strain displacement matrix of stiffener } \\
\text { element }\end{array}$ \\
\hline$c:$ & Rise of hypar shell \\
\hline$d_{s t}:$ & Depth of stiffener in general \\
\hline$d_{s x}, d_{s y}:$ & Depth of $X$ and $Y$ stiffeners, respectively \\
\hline$e:$ & $\begin{array}{l}\text { Eccentricity of stiffeners with respect to } \\
\text { midsurface of shell }\end{array}$ \\
\hline$e_{s x}, e_{s y}$ & $\begin{array}{l}\text { Eccentricities of } X \text { and } Y \text { stiffeners with } \\
\text { respect to mid surface of shell }\end{array}$ \\
\hline$E_{11}, E_{22}$ : & Elastic moduli \\
\hline$G_{12}, G_{13}, G_{23}:$ & $\begin{array}{l}\text { Shear moduli of a lamina with respect } \\
\text { to } 1,2 \text {, and } 3 \text { axes of fibre }\end{array}$ \\
\hline$h:$ & Shell thickness \\
\hline$M_{s x x}, M_{s y y}:$ & Moment resultants of stiffeners \\
\hline$n p:$ & Number of plies in a laminate \\
\hline
\end{tabular}

\begin{tabular}{|c|c|}
\hline$n_{x}, n_{y}:$ & $\begin{array}{l}\text { Number of stiffeners along } X \text { and } Y \\
\text { directions, respectively }\end{array}$ \\
\hline$N_{s x x}, N_{s y y}:$ & Axial force resultants of stiffeners \\
\hline$P:$ & $\begin{array}{l}\text { Ratio of the fundamental frequency of a } \\
\text { concentric punctured shell to that of a shell } \\
\text { without cutout expressed in percentage }\end{array}$ \\
\hline$Q_{s x x z}, Q_{s y y z}:$ & $\begin{array}{l}\text { Transverse shear resultants of } \\
\text { stiffeners }\end{array}$ \\
\hline$r:$ & $\begin{array}{l}\text { Ratio of the fundamental frequency of a shell } \\
\text { with an eccentric puncture to that of a shell } \\
\text { with concentric puncture expressed in } \\
\text { percentage }\end{array}$ \\
\hline$R_{x y}:$ & Radii of cross curvature of hypar shell \\
\hline$T_{s x x}, T_{s y y}$ & Torsion resultants of stiffeners \\
\hline$u_{s x}, w_{s x}$ & $\begin{array}{l}\text { Axial and transverse translational degrees of } \\
\text { freedom at each node of } X \text {-stiffener element }\end{array}$ \\
\hline$v_{s y}, w_{s y}:$ & $\begin{array}{l}\text { Axial and transverse translational degrees of } \\
\text { freedom at each node of } Y \text {-stiffener element }\end{array}$ \\
\hline$x, y, z:$ & Local co-ordinate axes \\
\hline$X, Y, Z:$ & Global co-ordinate axes \\
\hline$z_{k}:$ & $\begin{array}{l}\text { Distance of bottom of the kth ply from } \\
\text { midsurface of a laminate }\end{array}$ \\
\hline
\end{tabular}

$n_{x}, n_{y}: \quad$ Number of stiffeners along $X$ and $Y$

$N_{\text {sxx }}, N_{\text {syy }}: \quad$ Axial force resultants of stiffeners

$P$ : $\quad$ Ratio of the fundamental frequency of a concentric punctured shell to that of a shell stiffeners with an eccentric puncture to that of a shell with concentric puncture expressed in percentage

$R_{x y}: \quad$ Radii of cross curvature of hypar shell

$T_{s x x}, T_{s y y}: \quad$ Torsion resultants of stiffeners

$u_{s x}, w_{s x}: \quad$ Axial and transverse translational degrees of freedom at each node of $X$-stiffener element freedom at each node of $Y$-stiffener element midsurface of a laminate 
$\alpha_{s x}, \beta_{s x}$ : Rotational degrees of freedom at each node of $X$-stiffener element

$\alpha_{s y}, \beta_{s y}$ : Rotational degrees of freedom at each node of $Y$-stiffener element

$\delta_{\text {sxi }}, \delta_{\text {syi }}$ : Nodal displacement of stiffener element

$\nu_{12}, \nu_{21}$ : Poisson's ratios

$\rho: \quad$ Density of material

$\omega: \quad$ Natural frequency

$\bar{\omega}: \quad$ Non-dimensional natural

frequency $=\omega a^{2}\left(\rho / E_{22} h^{2}\right)^{1 / 2}$.

\section{References}

[1] J. N. Reddy, "Large amplitude flexural vibration of layered composite plates with cutouts," Journal of Sound and Vibration, vol. 83, no. 1, pp. 1-10, 1982.

[2] S. K. Malhotra, N. Ganesan, and M. A. Veluswami, "Vibration of composite plates with cut-outs," Journal of Aeronautical Society of India, vol. 41, pp. 61-64, 1989.

[3] B. Sivasubramonian, A. M. Kulkarni, G. V. Rao, and A. Krishnan, "Free vibration of curved panels with cutouts," Journal of Sound and Vibration, vol. 200, no. 2, pp. 227-234, 1997.

[4] K. Sivakumar, N. G. R. Iyengar, and K. Deb, "Free vibration of laminated composite plates with cutout," Journal of Sound and Vibration, vol. 221, no. 3, pp. 443-470, 1999.

[5] R. E. Rossi, "Transverse vibrations of thin, orthotropic rectangular plates with rectangular cutouts with fixed boundaries," Journal of Sound and Vibration, vol. 221, no. 4, pp. 733-736, 1999.

[6] M. Huang and T. Sakiyama, "Free vibration analysis of rectangular plates with variously-shaped holes," Journal of Sound and Vibration, vol. 226, no. 4, pp. 769-786, 1999.

[7] S. S. Hota and P. Padhi, "Vibration of plates with arbitrary shapes of cutouts," Journal of Sound and Vibration, vol. 302, no. 4-5, pp. 1030-1036, 2007.

[8] D. Chakravorty, P. K. Sinha, and J. N. Bandyopadhyay, "Applications of FEM on free and forced vibration of laminated shells," Journal of Engineering Mechanics, vol. 124, no. 1, pp. $1-8,1998$.

[9] B. Sivasubramonian, G. V. Rao, and A. Krishnan, "Free vibration of longitudinally stiffened curved panels with cutout," Journal of Sound and Vibration, vol. 226, no. 1, pp. 41-55, 1999.

[10] S. S. Hota and D. Chakravorty, "Free vibration of stiffened conoidal shell roofs with cutouts," Journal of Vibration and Control, vol. 13, no. 3, pp. 221-240, 2007.

[11] N. Nanda and J. N. Bandyopadhyay, "Nonlinear free vibration analysis of laminated composite cylindrical shells with cutouts," Journal of Reinforced Plastics and Composites, vol. 26, no. 14, pp. 1413-1427, 2007.

[12] S. Sahoo, "Free vibration of laminated composite hypar shell roofs with cutouts," Advances in Acoustics and Vibrations, vol. 2011, Article ID 403684, 13 pages, 2011.

[13] S. Sahoo and D. Chakravorty, "Finite element vibration characteristics of composite hypar shallow shells with various edge supports," Journal of Vibration and Control, vol. 11, no. 10, pp. 1291-1309, 2005.

[14] A. Mukherjee and M. Mukhopadhyay, "Finite element free vibration of eccentrically stiffened plates," Computers and Structures, vol. 30, no. 6, pp. 1303-1317, 1988.
[15] A. N. Nayak and J. N. Bandyopadhyay, "On the free vibration of stiffened shallow shells," Journal of Sound and Vibration, vol. 255, no. 2, pp. 357-382, 2003.

[16] A. Dey, J. N. Bandyopadhyay, and P. K. Sinha, "Finite element analysis of laminated composite paraboloid of revolution shells," Computers and Structures, vol. 44, no. 3, pp. 675-682, 1992. 

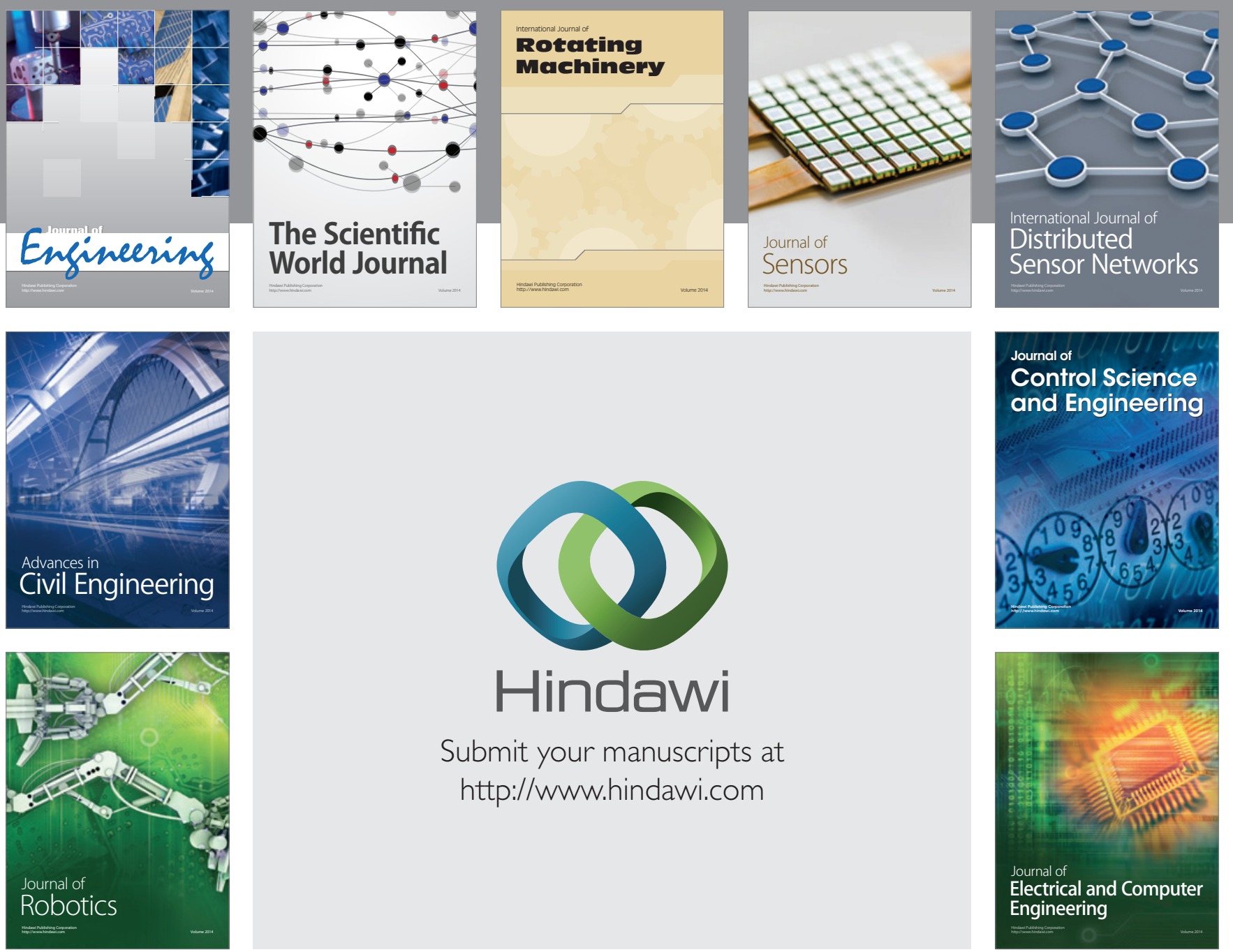

Submit your manuscripts at

http://www.hindawi.com
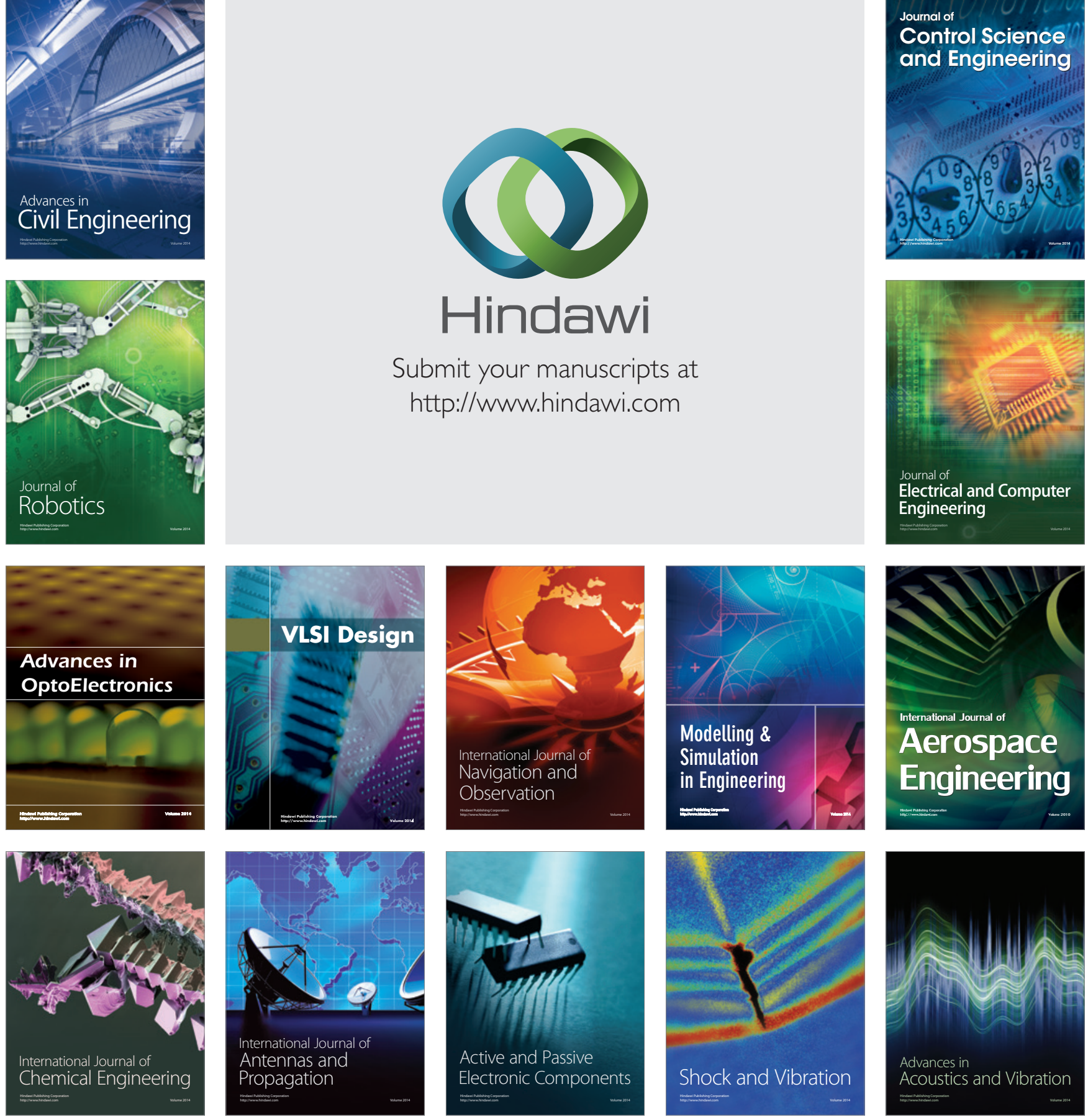